\title{
Online Shopping Characteristics and Its Determinants Among Online Shoppers in Kenya
}

\author{
Abdulrahman Noor Mohamed Liu Hongmin \\ Zhejiang University of Science and technology, School of Business
}

\begin{abstract}
There has been tremendous growth in online shopping globally, with many people transacting online boosted with increased internet penetration. The use of online transactions has recently increased in low- and middle-income countries. Kenya is one of the countries where online shopping is growing, boosted by an online and mobile money payment. Despite the growth, the online customers characteristics, preference behaviour and how it affects their online shopping intentions have rarely been explored. Besides, the factors that influence their online shopping preference behaviour are unknown due to a dearth of data.This study sought to characterise patterns of online shopping activities and determine factors influencing the online shopping preference behaviour in Kenya and how online shopping preference behaviour influences intention to shop online. This cross-sectional study was conducted among 225 conveniently recruited adults in Kenya who had ever bought a product online six months prior to the study. An online semi-structured questionnaire was used to collect data, and analysis was done using IBM Statistical Package for Social Sciences (SPSS) version 26.0. For descriptive statistics, frequencies and percentages were used for categorical variables and mean for Likert scale data. Cronbach Alpha was used to assess the reliability of the Likert scales. A correlation analysis was carried out before multivariate linear regression to determine the factors influencing consumer preference behaviour and online purchase intention. A P-value of $<$ 0.05 was considered statistically significant.Of the 225 participants, $55.1 \%$ were male, $179(79.6 \%)$ had a university level of education, and 106 (47.1\%) had formal employment. Most (55.6\%) used mobile phones apps to access online shopping platforms. Only 51 (22.7\%) shopped online frequently, $70.2 \%$ had shopped from more than one platform. Electronics $(45.8 \%)$ and clothing $(20.1 \%)$ were the most purchase products online, with "Mpesa" (mobile money payment) being the most used payment method for online shopping (57.3\%). On multivariate analysis, the convenience of online shopping, online shopping security, peer influence, and affordability were the statistically significant determinants of online shopping preference behaviour (P-value $<$ 0.05). Preference behaviour was, in turn, a significant predictor of intention to shop online (P-value $<0.001)$. In conclusion, online shopping in Kenya was used mainly by educated and working people who were more literate with higher incomes. Convenience, security, peer influence and affordability were key determinants of online preference behaviour; hence aspects that online marketers can focus on when venturing into the Kenyan online market to attract customers.
\end{abstract}

Keywords: Consumer behaviour, preference, online shopping; Kenya

DOI: $10.7176 / \mathrm{JMCR} / 82-04$

Publication date:September $30^{\text {th }} 2021$

\section{Introduction}

The increased global interconnectedness boosted by increased internet connection has proved an effective marketing tool and medium for global and local business transactions. Currently, e-commerce commands a huge market with enormous growth potential. The success of online shopping platforms, including Amazon, Alibaba and Tencent, has proved the online sales business's usefulness, with many businesses following suit to shift their transactions online (Kearney, 2015). Online shopping scope has greatly expanded with its use being influenced by factors that influence consumers internet use (Hwang \& Jeong, 2016) and the social networks around individuals, which are vital in information dissemination (Sunil, 2015).

With the global increase in the number of people choosing online shopping over traditional in-store shopping, including in Kenya, the Internet as a shopping medium is projected to grow further and rapidly. It offers a great business opportunity hence a target for many business managers and companies who aim to change their strategies and employ online sales approaches. This makes it essential to have information regarding the needs, patterns, behaviour, and preferences of online consumers

In Kenya, Online shopping is a sector that is growing tremendously. More online retailers are joining the Kenyan market, with companies such as Jumia, Glovo, Jiji, and Kilimall having established their presence locally. There has also been an increase in competition for the Kenyan online market, with many people, especially the youths, progressively preferring to shop online (Kabuba, 2014).

With the increase in the competition for online consumer attention by online businesses, there are also high expectations from online consumers, influenced by personal factors. Any online retailer must have a deep understanding of the online consumers' behaviours, including their needs and preferences.

With the Kenyan online shopping market gaining popularity, information regarding the consumers' 
preferences, shopping patterns and associated factors will be helpful to the companies looking to enter the Kenyan market and those already in the market to improve their online sales through an in-depth understanding of their potential customer characteristics and needs. Hence, this study aimed to assess the Kenyan online shoppers' characteristics and determine factors associated with online preference behaviour and effects on intention to purchase online in the future.

\subsection{Literature Review}

\subsubsection{Characteristics and patterns of online shopping}

Previous studies have pointed to increased online shopping with a decline or a constant number of physically instore shopping. In addition, most online shoppers experience has increasingly become positive (Pastore, 2000). Online consumers view online shopping to offer more information regarding the product and provide convenience and ease of purchase (Pastore, 2000). However, concerns regarding the security of transacting online hamper people's preference of online shopping and the need to physically view, touch, feel, or even fit the product before buying. Other concerns are the lack of a salesperson to speak to before purchasing a product with online shopping, challenges in processing refunds and returning products, and poor customer service (Vijayasarathy \& Jones, 2000). More young people shop online. The level of competency or literacy has also been highlighted to influence online shopping. The majority of those shopping online are literate and confident enough of their abilities to do so, as was the case in the USA (Lokken et al., 2003).

\subsubsection{Preference of Online Shoppers}

According to Kossecki (2005), six factors indicate trust-building to e-shops: (1) communication with clients. In this regard, Štefko et al., $(2015 \mathrm{a} ; 2015 \mathrm{c})$ state that web pages and e-shops can contain basic, as well as more detailed information, various updates, electronic documents, and can even provide direct communication with clients via online chat; (2) wide option of payment methods; (3) timely and safe shipment of goods; (4) quality post-sale service; (5) maintaining the privacy of clients; (6) external trust transfer.

In addition to the above, other authors also studied factors driving customers' online purchase intentions and satisfaction with e-shops. Padmaja and Mohan (2015) in their study on online consumers buying behaviour, observed that convenience, discounts and variety of options are the essential drivers of online purchase. In their study, Guo et al., (2012) outlined the importance of website design, security, information quality, payment method, which have a positive influence on customer satisfaction. The highlighted importance of "payment method" along with other factors in driving customer satisfaction.

A key determinant of customers' buying behaviour is brand loyalty (Capece et al., 2017), and it may be argued that the development of solid brands leads to the attenuation of the impact of cultural differences. In contrast, it has been shown that customer loyalty may be influenced by customers' perception concerning the extent to which a company is socially responsible, and the importance of the relationship may differ in different social contexts (Brogi et al., 2013). Other important factors of consumer trust are image and reputation - they are interconnected, while the current image of a subject is usually based on its previous reputation (Štefko et al., 2015b), Teltzrow et al. (2007) have found that perceived privacy concerns have the strongest influence on trust in the e-shop, followed by perceived reputation and perceived size of the offline stores.

\section{Methodology}

This was a cross-sectional study conducted among conveniently selected individuals in Kenya who had shopped online. A total of 225 participants were included in the study. Data was collected using an online semi-structured questionnaire. The questionnaire had three sections. The first section was on the demographic characteristics of the participants, including their gender, religion, marital status, occupation, level of education and income. The second part included questions on their online shopping patterns, including products they shopped online, number of platforms shopped from, devices they used to access online shopping platforms, the amount spent online, and payment methods. The last section included Likert scale questions on their online shopping preference behaviour, online shopping convenience, security, affordability, media influence, peer influence and intention to purchase online. The questions included in the questionnaire were derived from related published literature in journal articles, while the authors generated others considering the local study context, study objectives and background knowledge.

The questionnaire was converted into an online Google form, and the link was shared, inviting eligible participants via social media platforms including Facebook, WhatsApp, and Twitter. The first page of the form explained the study's aims and asked for participants' consent to participate in the study. They then completed two questions assessing their eligibility, including asking if they were aged 18 years and above if they had ever shopped online in the last six months. Those who selected no to any of the eligibility questions were not eligible and could not continue with the survey.

The collected data was imported into Microsoft Excel, where it was cleaned, checked for completeness, and a copy back-up on a password-protected drive. The data was then imported into IBM Statistical Package for Social Sciences (SPSS) Version 26.0, coded and analysed. For descriptive analysis, the categorical variables were 
analysed using frequencies and percentages. The Likert scale data were described using means and standard deviation. The reliability of the Likert scales was assessed using Cronbach Alpha. For inferential analysis, Pearson's correlation test was used to determine the association between the different factors and preference behaviour and intention to purchase online in future. The linear and multiple regression model was used to determine the factors influencing online preference behaviour. Multiple linear regression was also used to determine the effect of online preference behaviour on intention to shop online in future after controlling for other factors. A p-value of $<0.05$ was considered statistically significant.

\section{Results}

\subsection{Characteristics of participants}

Of the 225 participants in the survey, 124 (55.1\%) were male while $101(44.9 \%)$ were female. Most, $(179 ; 79.6 \%)$ had attained University level of education, 32 (14.2\%) college, 9 (4.0\%) secondary school education, 4 (1.8\%) primary school education while $1(0.4 \%)$ did not have any formal education. Majority $(106 ; 47.1 \%)$ had formal employment, 55 (24.4\%) were students, 26 (11.6\%) were self-employed, 21 (.3\%) were unemployed, $15(6.7 \%)$ were businesspersons, and $2(0.9 \%)$ were farmers.

Among them, $145(64.4 \%)$ were single, $76(33.8 \%)$ were married, $3(1.3 \%)$ divorced and $1(0.4 \%)$ widowed. On monthly income, $82(36.4 \%)$ had a monthly income above U\$ 500, $45(20.0 \%)$ less than U\$ 50, $38(16.9 \%)$ U\$ 50- 200, 33 (14.7\%) U\$ 201- 350 and 27 (12.0\%) U\$ 351- 500. (Table 1)

Table 1: Participants demographic characteristics

\begin{tabular}{lll}
\hline Demographic characteristics & Frequency $(\mathrm{n})$ & Percentage $(\%)$ \\
\hline Gender & 124 & $55.1 \%$ \\
Male & 101 & $44.9 \%$ \\
Female & 179 & $79.6 \%$ \\
\hline Level of education & 32 & $14.2 \%$ \\
University education & 9 & $4.0 \%$ \\
College & 4 & $1.8 \%$ \\
Secondary school education & 1 & $0.4 \%$ \\
Primary school education & & \\
No formal education & 106 & $47.1 \%$ \\
\hline Employment & 55 & $24.4 \%$ \\
Formal employment & 26 & $11.6 \%$ \\
Student & 21 & $9.3 \%$ \\
Self-employment & 15 & $6.7 \%$ \\
Unemployed & 2 & $0.9 \%$ \\
Businesspersons & & \\
Farmers & 145 & $64.4 \%$ \\
\hline Marital status & 76 & $33.8 \%$ \\
Single & 3 & $1.3 \%$ \\
Married & 1 & $0.4 \%$ \\
Divorced & & \\
Widowed & 45 & $20.0 \%$ \\
\hline Monthly income & 38 & $16.9 \%$ \\
Less than $\$ 50$ & 33 & $14.7 \%$ \\
\$50-200 & 27 & $36.4 \%$ \\
\$201-350 & 82 & \\
More than $\$ 500$ & & \\
\hline
\end{tabular}

\subsection{Online shopping characteristics and patterns}

Of the participants in the study, $224(99.6 \%)$ use the Internet, while all had ever purchased a product online. Most, $87(38.7 \%)$ had been shopping online for 3-5 years, $53(23.6 \%) 1-2$ years, $44(19.6 \%)$ less than one year, while 41 $(18.2 \%)$ for more than five years. To access the online shopping platforms, $125(55.6 \%)$ used mobile phone apps, $82(36.4 \%)$ websites, $17(7.6 \%)$ online shopping agents, while $1(0.4 \%)$ participant used all the above modes.

Most $(188 ; 83.6 \%)$ preferred to use smartphones to access the online shopping platform, $30(13.3 \%)$ personal computers including laptop and desktop, $5(2.2 \%)$ tablets while $2(0.9 \%)$ preferred using both computer, smartphone, and tablet. A majority, $(139 ; 61.8 \%)$ shopped online sometimes, $51(22.7 \%)$ frequently while 35 (15.6\%) rarely shopped online. Most of the participants had shopped from more than two online platforms $(89 ; 39.5 \%)$, followed by those who shopped from 2 platforms $(69 ; 30.7 \%)$ and one platform $(67 ; 29.8 \%)$, respectively. The maximum number of platforms an individual had shopped from was 20 (Table 2). 
Table 2: Online shopping characteristics and patterns

\begin{tabular}{|c|c|c|}
\hline Behaviour & Frequency (n) & Percent $(\%)$ \\
\hline \multicolumn{3}{|l|}{ Use Internet } \\
\hline Yes & 224 & 99.6 \\
\hline No & 1 & 0.4 \\
\hline \multicolumn{3}{|c|}{ Ever purchased a product online } \\
\hline Yes & 225 & 100.0 \\
\hline \multicolumn{3}{|l|}{ Period of online shopping } \\
\hline Less than one year & 44 & 19.6 \\
\hline $1-2$ years & 53 & 23.6 \\
\hline $3-5$ years & 87 & 38.7 \\
\hline More than five years & 41 & 18.2 \\
\hline \multicolumn{3}{|c|}{ Mode of accessing online shopping } \\
\hline Mobile phone app & 125 & 55.6 \\
\hline Website & 82 & 36.4 \\
\hline Use of online shop agent & 17 & 7.6 \\
\hline All & 1 & 0.4 \\
\hline \multicolumn{3}{|c|}{ Device preferred to access online shopping system } \\
\hline PC (Laptop and Desktop) & 30 & 13.3 \\
\hline Smartphone & 188 & 83.6 \\
\hline Tablet & 5 & 2.2 \\
\hline Both & 2 & 0.9 \\
\hline \multicolumn{3}{|c|}{ Frequency of online shopping } \\
\hline Frequent & 51 & 22.7 \\
\hline Rarely & 35 & 15.6 \\
\hline Sometime & 139 & 61.8 \\
\hline \multicolumn{3}{|c|}{ No of the platforms shopped from } \\
\hline 1 & 67 & 29.8 \\
\hline 2 & 69 & 30.7 \\
\hline More than 2 & 89 & 39.5 \\
\hline
\end{tabular}

On the amount spend on online shopping for the 6 months prior to the study, $111(49.3 \%)$ spend less than Ksh 10,000 (U\$100), 48 (21.3\%) Ksh 10,000- 30,000 (U\$100-300), 30 (13.3\%) Ksh 30,000-50,000 (U\$300-500), 15 (6.7\%) Ksh 50,000-80,000 (U\$500-800), 12 (5.3\%) Ksh 80,000-100, 000 (U\$ 800-1,000) and 9 (4.0\%) above Ksh 100,000 (U\$1,000).

Most of the participants $(103 ; 45.8 \%)$ had purchased electronics online, followed by clothing's $(45 ; 20.0 \%)$, foods and drinks $(38 ; 16.9 \%)$, and beauty products $(24 ; 10.7 \%)$. (Table 3).

Table 3: Product shopped online.

\begin{tabular}{lll}
\hline The product frequently bought online & Frequency $(\mathrm{n})$ & Percent $(\%)$ \\
\hline Baby stuff & 2 & .9 \\
Beauty products & 24 & 10.7 \\
Books & 1 & .4 \\
Clothing & 45 & 20.0 \\
Credit & 1 & .4 \\
Digital content, like courses, videos games & 1 & .4 \\
Electronics & 103 & 45.8 \\
Food and drinks & 38 & 16.9 \\
House items & 1 & .4 \\
Jewellery & 1 & .4 \\
Medical products & 5 & 2.2 \\
None & 2 & .9 \\
Phones & 1 & .4 \\
\hline Mode of payment for online shopping & & \\
Mobile money (Mpesa) & 129 & 57.3 \\
Cash on delivery & 70 & 31.1 \\
Debit/credit card & 24 & 10.7 \\
Paypal/pesapal & 2 & 0.9 \\
\hline
\end{tabular}

A majority $(129 ; 57.3 \%)$ of the participants paid via mobile money (Mpesa) for their online shopping, 70 (31.1\%) paid cash on delivery, 24 (10.7\%) used debit/credit card, while $2(0.9 \%)$ paid by PayPal/Pesapal. 
Only $51(22.7 \%)$ went to view the product in the shop before purchasing online. There was a statistically significant association between gender and viewing the product in the shop before purchasing it online. A high proportion of men $(28.2 \%)$ went to view the product in the shop before purchasing online compared to $15.8 \%$ females. The difference was statistically significant $(\mathrm{P}$ value $=0.020)$ (Table 4).

Table 4: Gender differences with regards to the physical viewing of products before purchasing online

\begin{tabular}{llll}
\hline Gender & View product physically & $\begin{array}{l}\text { Do not view product } \\
\text { physically }\end{array}$ & P value \\
\hline Male & $35(28.2 \%)$ & $89(71.8 \%)$ & 0.020 \\
Female & $16(15.8 \%)$ & $85(84.2 \%)$ & \\
\hline
\end{tabular}

Family and friend's recommendation was the primary source of information regarding online shopping platforms $(80 ; 35.6 \%)$, followed by website adverts $(62 ; 27.6 \%)$, press and media adverts $(45 ; 20.0 \%)$ and search engines $(29 ; 12.9 \%)$.

Table 5: Information sources

\begin{tabular}{lll}
\hline Source of information on shopping website & Frequency $(\mathrm{n})$ & Percent $(\%)$ \\
\hline Advertising & 1 & .4 \\
All the above & 1 & .4 \\
Email links & 4 & 1.8 \\
Facebook & 2 & .9 \\
Family/Friend recommendations & 80 & 35.6 \\
Press and Media adverts & 45 & 20.0 \\
Search Engines & 29 & 12.9 \\
Website Advert & 62 & 27.6 \\
WhatsApp & 1 & .4 \\
\hline Total & 225 & 100.0 \\
\hline
\end{tabular}

\subsection{Online shopping preference behaviour and associated factors}

The online shopping preference behaviour scale, Convivence scale, security scale, peer influence scale and media influence scale were reliable, with a Cronbach's alpha of $>0.6$. There was a high positive correlation between online shopping preference behaviour and convenience of shopping online $(\mathrm{r}=0.63, \mathrm{P}$ value $<0.001)$, perceived security of online shopping $(\mathrm{r}=0.57, \mathrm{P}$ value $<0.001)$, peer influence to shop online $(\mathrm{r}=0.59, \mathrm{P}$ value $<0.001)$ and intention to buy online $(\mathrm{r}=0.56$, $\mathrm{P}$-value $<0.001)$.

There was a highly significant medium positive correlation between online shopping preference behaviour and affordability of the product $(\mathrm{r}=0.31, \mathrm{P}$ value $<0.001)$, and a small positive correlation between online shopping preference behaviour and the influence of the media $(\mathrm{r}=0.19, \mathrm{P}$ value $=0.005)$, which was statistically significant (P -value $<0.001$ ). (Table 6).

Table 6: Correlation between online preference behavior and other factors

\begin{tabular}{llr}
\hline Factors & Pearson's correlation coefficient (r) & P value \\
\hline Convenience & 0.632 & $<0.001$ \\
Security & 0.572 & $<0.001$ \\
Peer influence & 0.594 & $<0.001$ \\
Affordability & 0.312 & $<0.001$ \\
Media & 0.187 & 0.005 \\
Intention to buy online & 0.556 & $<0.001$ \\
\hline
\end{tabular}

On multiple linear regression, the independent variables could explain 59.3\% variability in online shopping preference behaviour $\left(\mathrm{R}^{2}=0.593\right)$. The F-test was highly significant; thus, the model explained a significant amount of the variance in online shopping preference behaviour, $(\mathrm{F}(5,219)=66.17, \mathrm{p}<.0001)$.

The convenience of online shopping, security of online shopping, peer influence, and affordability were statistically significant determinants of online shopping preference behaviour (P-value $<0.05)$. (Table 7). 
Table 7: Multiple linear regression showing significant determinants of online shopping preference behaviour.

\begin{tabular}{lllllll}
\hline Model & \multicolumn{2}{l}{ Unstandardised B } & Standardised B & $\mathrm{t}$ & Sig. & \multicolumn{2}{l}{$95.0 \%$ CI for B } \\
\cline { 2 - 4 } \cline { 6 - 8 } & $\mathrm{B}$ & S.E. & Beta & & & \\
\hline (Constant) & .426 & .209 & & 2.041 & .042 & $.015-.837$ \\
mean convenience score & .344 & .048 & .373 & 7.177 & $<0.001$ & $.249-.438$ \\
mean security score & .202 & .049 & .223 & 4.123 & $<0.001$ & $.105-.298$ \\
mean peer score & .269 & .040 & .335 & 6.715 & $<0.001$ & $.190-.349$ \\
mean media score & .041 & .035 & .053 & 1.154 & .250 & $-.029-.111$ \\
mean affordability & .067 & .032 & .095 & 2.103 & .037 & $.004-.130$ \\
\hline
\end{tabular}

3.4 Effect of online shopping preference behaviour on intention to purchase online in future.

There was a moderate positive significant correlation between intention to purchase online and convenience of online shopping ( $\mathrm{r}=0.41$, $\mathrm{P}$ value $=0.001)$, security of online shopping $(\mathrm{r}=0.36, \mathrm{P}$ value $<0.001)$, and peer influence on online shopping $(\mathrm{r}=0.33, \mathrm{P}$ value $<0.001)$. There was a small significant positive correlation between intention to purchase online and media influence $(\mathrm{r}=0.13$, $\mathrm{P}$-value $=0.048)$ (Table 8).

Table 8: Pearson correlation between intention to purchase online and other factors.

\begin{tabular}{lll}
\hline Factor & Pearson's correlation coefficient & P value \\
\hline Convenience & 0.408 & $<0.001$ \\
Security & 0.356 & $<0.001$ \\
Peer influence & 0.332 & $<0.001$ \\
Media & 0.132 & 0.048 \\
Affordability & 0.74 & 0.266 \\
\hline
\end{tabular}

The independent variables explained $32.8 \%$ of the variability in the intention to shop online in future $\left(\mathrm{R}^{2}=0.328\right)$, and the independent variables significantly predicted the intention to shop online in future, $\mathrm{F}(6,218)$ $=17.722, \mathrm{p}<0.001$. Only preference behaviour was a significant predictor of intention to shop online on multivariate analysis after accounting for the other factors (Table 9).

Table 9: Multiple linear regression showing association between intention to shop online and consumer preference behaviour.

\begin{tabular}{|c|c|c|c|c|c|c|}
\hline \multirow[t]{2}{*}{ Model } & \multicolumn{2}{|c|}{ Unstandardised B } & Standardised B & \multirow[t]{2}{*}{$-\mathrm{t}$} & \multirow{2}{*}{\multicolumn{2}{|c|}{ Sig. $95.0 \% \mathrm{CI}$ for $\mathrm{B}$}} \\
\hline & $\mathrm{B}$ & S.E. & Beta & & & \\
\hline (Constant) & .508 & .456 & & 1.113 & .267 & $-.391-1.407$ \\
\hline mean convenience score & .103 & .115 & .067 & .894 & .372 & $-.124-.331$ \\
\hline mean security score & .091 & .110 & .061 & .830 & .408 & $-.126-.309$ \\
\hline mean peer score & .011 & .096 & .008 & .116 & .908 & $-.177-.199$ \\
\hline mean media score & .058 & .077 & .045 & .755 & .451 & $-.094-.210$ \\
\hline mean affordability & -.136 & .070 & -.115 & -1.936 & .054 & $-.273-.002$ \\
\hline mean preference score & .835 & .146 & .501 & 5.698 & .000 & $.546-1.123$ \\
\hline
\end{tabular}

\section{DISCUSSION}

\subsection{Characteristics of participants}

Most of the people who shop online in this study were male (55.1\%), in line with previous studies where men shop online more or prefer online shopping compared to females (Rajamma \& Neeley, 2005; Van Slyke, Comunale, \& Belanger, 2002). This contradicts traditional literature on shopping where women were considered responsible for shopping. Shopping has long been considered a gendered activity. The urbanisation and workforce changes and associated social changes are likely to have resulted in the observed changes. Men who have attained transcendence of gender roles do shop just as women do (Otnes \& McGrath, 2001).

With the changes in shopping strategies from physical shops to online shopping, it is likely to be attractive to men who used to dislike going physically to shop, which was against the social norms. As reported by (Alreck \& Settle, 2002), a person's adoption of a given shopping strategy is dependent on their preference and how they like or view it. Those who did not like traditional in-store shopping will try to use new strategies like online shopping, which saves their time and effort. It is believed that men do not like physical shopping, which is irritating to them. They are more likely to prefer online shopping; hence shop from it more compared to women. An alternative explanation to more men shopping online than women is the perceived risk of online shopping. Women fear buying online for perceived high risks compared to men, who are more likely to take risks (Garbarino \& Strahilevitz, 2004).

However, contrary to this assertion, other studies have found more females to shop online than men in terms of the population and expenditure on online shopping despite being the ones with serious concerns regarding risks 
of online shopping (Dai, 2007). While the reported pattern of internet use may influence online shopping practices with regards to gender, this is likely to vary depending on the occupations and individual characteristics (Losh, 2003).

More educated and employed individuals were the majority of those who shopped online in the study, followed by students. This is in line with previous studies where highly educated individuals, those with high income and students were found to be highly likely to shop online. Highly educated people are likely to be more informed, well versed with technology, able to access Internet; hence highly likely to use the Internet compared to those with low level or no education (Odike, Mbah, \& Akpan, 2019). Tarafdar and Vaidya pointed out that a low level of education acts as a barrier to internet use, indicating the crucial role of education in utilising online services (Tarafdar \& Vaidya, 2006). Hence this explains the high number of educated people in this study. Besides, it was an online survey hence the population which was more likely to be reached were the educated individuals.

The majority of the participants were working and hence income earners. This was in agreement with previous studies that have found an association between high income or employment and online shopping. Income and per capita gross domestic product have been demonstrated to influence online shopping (Hwang \& Jeong, 2016). Besides, the use of the Internet is strongly correlated with income (Lightner, Yenisey, Ozok, \& Salvendy, 2002), while income is vital in influencing online shopping practices.

\subsection{Online shopping characteristics}

Most had been shopping online for one year and more. People who had shopped online previously were more likely to shop online again. In some people, online shopping becomes addictive; hence continuously shop online (Gunuc \& Keskin, 2016). To others, the ease of online shopping, the available incentives and motivation influence their decision to continuously shop online (Khatibi, Haque, \& Karim, 2006). Hence, having shopped online for more than a year might have resulted from the motivation and benefits of it, such as ease of shopping online and convenience.

More than half of the study participants shopped online using their mobile phones apps, with $83.6 \%$ preferring to use their smartphones for shopping. This is not surprising due to the increased penetration of smartphone use globally. Besides, m-commerce using phones has been estimated to surpass electronic commerce via websites due to increased internet penetration globally, improved network connections, the proliferation of social media and rapid advancements in mobile technologies (Wang, Xiang, \& Fesenmaier, 2014). For example, in the USA, mobile devices were used by consumers more (52\%) to do online shopping on Thanksgiving Day in 2014 compared to personal computers use (IBM, 2015). This points to the popularity of mobile devices for online shopping among consumers.

However, only $15.6 \%$ were frequent online shoppers in the study, while $61.8 \%$ did it sometimes. This is online with previous survey findings where most online shoppers shop online occasionally or infrequently (Statista, 2018). Hence, it is likely that online shopping has not replaced physical store shopping entirely as shoppers buy a limited number of products online, with most stilly being bought in stores.

Mobile payment (Mpesa) was the most preferred payment method for online shopping. This is in contrast to the practice in Bangladesh where online shopping was mainly paid by cash on delivery by most people $(76 \%)$, with only $15.6 \%$ paying by debit card and $5 \%$ by mobile banking (Rahman, Islam, Esha, Sultana, \& Chakravorty, 2018). Cash on delivery was also the preferred payment method in a study in India (Rastogi, 2010). However, in China, most online shoppers were found to pay via debit or credit cards (Liao, Chu, Chen, \& Chang, 2012). The notable differences in countries may be due to the differences in the established financial system in those countries hence customer preferences. In Kenya, Mobile money payment services (Mpesa) are the widely used and established form of cash transfer and payment hence the likely reason for its preference for online shopping payment.

\subsection{Effect of online shopping characteristics and preference behaviour on intention to purchase online in future}

In line with the findings of this study, $\mathrm{Li}$ and Zhang found a positive relationship between online shopping behaviours and product characteristics and information characteristics (Li \& Zhang, 2002). Similarly, Vellido, Lisboa and Meehan found the perceived security to be a key determinant of consumer perceptions on online shopping (Vellido, Lisboa, \& Meehan, 2000). Consumer behaviour was also influenced by the trust the consumer has in the online retailer and the size of the retailer in the market (Jarvenpaa, Tractinsky, \& Vitale, 2000).

Unlike in this study where online consumer preference was the only significant determinant of intention to shop online in future, a study by Chiu, Lin and Tang found convenience or ease of use, perceived security, perceived usefulness and innovativeness of an individual to be the critical determinant of online purchase intention (Chiu, Lin, \& Tang, 2005). Similarly, Lee, Fiore and Kim found perceived enjoyment and usefulness to be the key predictors of intention to shop online (Lee, Kim, \& Fiore, 2010). The individual perceived usefulness of the product was a crucial determinant in an individual's intention to purchase online, as found in the study by (Pan, 
Chaipoopirutana, \& Combs, 2010).

Online individual behaviour was shown to influence individuals shopping decisions (Hu et al., 2009). People around individuals and their attitude was found to affect their behaviour regarding online purchase in Thailand (Laohapensang, 2009). as was the case in this study. This, in turn, influenced purchase intention, eventually resulting in actual buying action (Laohapensang, 2009). However, purchase intention does not always lead to the actual purchase practice (Kim \& Jones, 2009), but might positively push online purchase decisions. Hence understanding the behaviour of the potential customers is key in attracting them and developing a positive relationship (E. Kim \& Hong, 2010). This relationship requires further investigation.

\section{CONCLUSION}

In conclusion, online shopping in Kenya was mostly used by educated and working people who were more literate with higher incomes. Convenience, security, peer influence and affordability were key determinants of online preference behaviour. Hence, online marketers can focus on when venturing into the Kenyan online market to attract customers. However, more research is required to understand the other factors that influence online consumer behaviour and intention to shop online. Besides, there is a need to understand online shopping patterns among online consumers using large population-based studies to provide representative information that will be key in informing investment decisions by businesses with plans to venture into the Kenyan online market.

\section{References}

Alreck, P., \& Settle, R. B. (2002). Gender effects on Internet, catalogue and store shopping. Journal of Database Marketing \& Customer Strategy Management, 9(2), 150-162.

Chiu, Y. B., Lin, C. P., \& Tang, L. L. (2005). Gender differs: assessing a model of online purchase intentions in e - tail service. International journal of service industry management.

Dai, B. (2007). The impact of online shopping experience on risk perceptions and online purchase intentions: the moderating role of product category and gender.

Garbarino, E., \& Strahilevitz, M. (2004). Gender differences in the perceived risk of buying online and the effects of receiving a site recommendation. Journal of Business Research, 57(7), 768-775.

Gunuc, S., \& Keskin, A. D. (2016). Online shopping addiction: Symptoms, causes and effects. Addicta: The Turkish Journal on Addictions, 3(3), 353-364.

Hu, Y., Sun, X., Zhang, J., Zhang, X., Luo, F., \& Huang, L. (2009). A university student behavioral intention model of online shopping. Paper presented at the 2009 International Conference on Information Management, Innovation Management and Industrial Engineering.

Hwang, Y., \& Jeong, J. (2016). Electronic commerce and online consumer behavior research: A literature review. Information Development, 32(3), 377-388.

IBM. (2015). U.S. Retail - Black Friday Report 2015 Retrieved from http://www-01.ibm.com/software/marketingsolutions/benchmark-reports/black-friday-2015.html

Jarvenpaa, S. L., Tractinsky, N., \& Vitale, M. (2000). Consumer trust in an Internet store. Information technology and management, $1(1), 45-71$.

Kabuba, P. K. (2014). E-commerce and performance of online businesses in Kenya. University of Nairobi,

Kearney, A. (2015). The 2015 Global retail E-Commerce index: Global retail E-Commerce keeps on clicking. Chicago: AT Kearney.

Khatibi, A., Haque, A., \& Karim, K. (2006). E-Commerce: A study on internet shopping in Malaysia. Journal of Applied Sciences, 6(3), 696-705.

Kim, S., \& Jones, C. (2009). Online shopping and moderating role of offline brand trust. Direct Marketing: An International Journal.

Laohapensang, O. (2009). Factors influencing internet shopping behaviour: a survey of consumers in Thailand. Journal of fashion marketing and management: An international journal.

Lee, H.-H., Kim, J., \& Fiore, A. M. (2010). Affective and cognitive online shopping experience: Effects of image interactivity technology and experimenting with appearance. Clothing and textiles research Journal, 28(2), $140-154$

Li, N., \& Zhang, P. (2002). Consumer online shopping attitudes and behavior: An assessment of research. AMCIS 2002 proceedings, 74.

Liao, S.-h., Chu, P.-h., Chen, Y.-j., \& Chang, C.-C. (2012). Mining customer knowledge for exploring online group buying behavior. Expert Systems with Applications, 39(3), 3708-3716.

Lightner, N. J., Yenisey, M. M., Ozok, A. A., \& Salvendy, G. (2002). Shopping behaviour and preferences in ecommerce of Turkish and American university students: implications from cross-cultural design. Behaviour \& Information Technology, 21(6), 373-385.

Lokken, S. L., Cross, G. W., Halbert, L. K., Lindsey, G., Derby, C., \& Stanford, C. (2003). Comparing online and non - online shoppers. International Journal of Consumer Studies, 27(2), 126-133. 
Losh, S. C. (2003). Gender and educational digital chasms in computer and Internet access and use over time: 1983-2000. IT \& Society, 1(4), 73-86.

Odike, M. N., Mbah, C. C., \& Akpan, A. O. (2019). Effect of education on online shopping behaviour in nigeria. Godfrey Okoye University, Enugu.

Otnes, C., \& McGrath, M. A. (2001). Perceptions and realities of male shopping behavior. Journal of retailing, 77(1), 111-137.

Pan, Y., Chaipoopirutana, S., \& Combs, H. (2010). A study of the factors influencing online purchase intention of consumers in China. American society of business and behavioral sciences, 6(1), 88-99.

Pastore. (2000). Stores vs. web sites: the battle continues. Retrieved from URL http:// cyberatlas.internet.com/markets/retailing/article/ 0,6061 482461,00.html

Rahman, M. A., Islam, M. A., Esha, B. H., Sultana, N., \& Chakravorty, S. (2018). Consumer buying behavior towards online shopping: An empirical study on Dhaka city, Bangladesh. Cogent Business \& Management, $5(1), 1514940$.

Rajamma, R. K., \& Neeley, C. R. (2005). Antecedents to shopping online: A shopping preference perspective. Journal of Internet Commerce, 4(1), 63-78.

Rastogi, A. K. (2010). A Study of Indian Online Consumers \& Their Buying Behaviour. International Research Journal, 1(10), 80-82.

Statista. (2018). Online shopping frequency according to online shoppers worldwide as of October 2018. Retrieved from https://www.statista.com/statistics/664770/online-shopping-frequency-worldwide/

Sunil. (2015). Trends and practices of consumers buying online and offline: an analysis of factors influencing consumer's buying. International Journal of Commerce and Management, 25(4), 442-455.

Tarafdar, M., \& Vaidya, S. D. (2006). Challenges in the adoption of E-Commerce technologies in India: The role of organizational factors. International Journal of Information Management, 26(6), 428-441.

Van Slyke, C., Comunale, C. L., \& Belanger, F. (2002). Gender differences in perceptions of web-based shopping. Communications of the ACM, 45(8), 82-86.

Vellido, A., Lisboa, P. J., \& Meehan, K. (2000). Quantitative characterization and prediction of on-line purchasing behavior: A latent variable approach. International journal of electronic commerce, 4(4), 83-104.

Vijayasarathy, L. R., \& Jones, J. M. (2000). Print and Internet catalog shopping: assessing attitudes and intentions. Internet Research.

Wang, D., Xiang, Z., \& Fesenmaier, D. R. (2014). Adapting to the mobile world: A model of smartphone use. Annals of Tourism Research, 48, 11-26. 